\title{
LIFE CYCLE AND COST ANALYSIS FOR MODULAR RE-CONFIGURABLE FINAL ASSEMBLY SYSTEMS
}

\author{
Juhani Heilala, Kaj Helin, Jari Montonen, Otso Väätäinen \\ VTT Industrial Systems, P.O.Box 1702, FIN-02044 VTT, Finland
}

\begin{abstract}
This article presents a case study in the design of a modular semi-automated reconfigurable assembly system using life cycle cost analysis methodology. To ensure that an assembly system is appropriately designed, system measurement schemes should be established for determining and understanding design effectiveness. Understanding life cycle costs is the first step toward increasing profits. The authors are developing an analysis tool that integrates Overall Equipment Efficiency (OEE), Cost of Ownership (COO), and other analysis methods to improve the design of flexible, modular reconfigurable assembly systems. The development is based on selected industrial standards and the authors' own experience in modular assembly system design and simulation. The developed TCO (Total Cost of Ownership) methodology is useful in system supplier and end-user communication and helps in trade-off analysis of the system concepts.
\end{abstract}

Key words: Modular Assembly System Design, Cost of Ownership Analysis, Overall Equipment Efficiency

\section{INTRODUCTION}

The objective of modern assembly processes is to produce high quality customized products at low cost. To ensure that an assembly system is appropriately designed, system measurement schemes should be established for determining and understanding design effectiveness. Measurements can be classed in two categories: cost and performance. Understanding manufacturing costs already in the system design phase is the first step to 
increasing profits. Throughput, utilization, and cycle time continue to be emphasized as key performance indicators for existing operations and for the planning of new assembly systems, and they have an influence on the cost efficiency of the system. All life cycle related cost issues should be identified and analyzed before making investment decisions, as early as possible in the system design phase.

The authors are developing an analysis tool that integrates Overall Equipment Efficiency (OEE), Cost Of Ownership (COO) and other analysis methods to improve designs of flexible, modular re-configurable assembly systems. The Total Cost of Ownership (TCO) analysis tool development is based on selected semiconductor industry standards $s^{1,2,3}$ and is applied now for electronics final assemblies and the authors' own experience from assembly system design and simulation. The TCO method is useful in system supplier and end-user communication and helps in trade-off analysis of the system concepts (Figure 1).

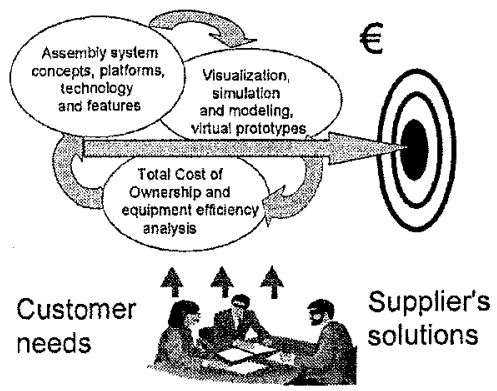

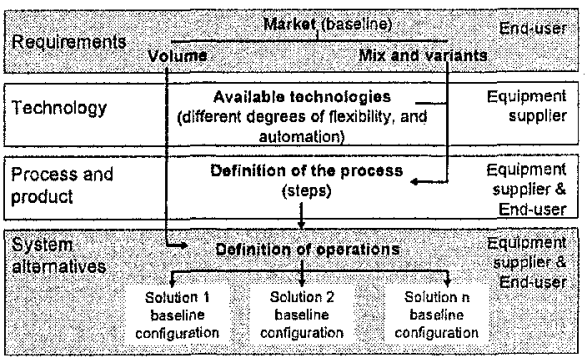

Figure 1. Collaborative assembly system design between end-user and system supplier.

\section{DEVELOPMENT OF ASSEMBLY SYSTEM DESIGN AND ANALYSIS METHODS}

Cost issues, especially reduction of cost, are key issues when investing new assembly hardware or processes. This was clearly shown in the assembly survey done by Assembly Magazine ${ }^{4}$ in 2004. The purchase cost of the system is just one parameter to consider when performing a cost of ownership analysis. Different cost estimation methods have been devised; a few of them measure intangible costs such as flexibility, product yield, parts quality, process time variation, system modularity, re-use value, and so on. Although not all of these intangibles are easily understood, their costs may be measured by indirect methods. In many cases, a cost estimation method 
can be derived from performance measurements. For example, flexibility affects the capital investment plan. Yield and quality are related to capacity and material handling costs. Process time variation may cause problems with workstation utilization or in-process inventories ${ }^{5}$.

\subsection{Modular re-configurable assembly systems}

Modular structure and reconfiguration is needed in the current market climate, where system changes occur at ever shorter intervals (Table 1).

Table 1. Typical Life-cycle parameters in electronics industry ${ }^{6}$

\begin{tabular}{ll}
\hline Parameters & Life-cycle parameter values \\
\hline Typical aggregate annual volume & Less than 10000 \\
& More than 1 million, up to 8 million \\
Product Mix - a logical family & Typically 2-8 variants \\
Typical life of products in production & 6 months - 3 years, up to 15 years \\
Frequency of new product introductions & Computers: $1-2$ months, up to 10 variants, \\
& others typically from 4 months to 2 year \\
Assembly rate objective & Starting 2-25/hour high-end products, \\
good/units/hour & $250-1000 /$ hour, consumer products, as high as \\
& $3000 /$ hour \\
\hline
\end{tabular}

The use of a modular structure in the architecture of an assembly system has many advantages. It facilitates standardization in that at least the selected suppliers' modules are compatible and the system is scalable. Design of a modular system is just like selecting suitable modules from a catalog and placing them in the right order to achieve the correct process flow and system layout. The end-user and system integrator can more easily configure the system and later reconfigure it to meet the customer's future needs.

Modularity is also a cost-efficient solution; it supports step-by-step investment, and later upgrades or modifications to the system are also easier. Standardized building blocks also help in calculating the cost of investment. Most of the modules should be standard, with known catalogue prices. Thus, product-related special customization is minimized. Typically, some equipment vendors estimate that $85 \%$ of the final assembly system equipment is re-usable in electronics final assembly ${ }^{6}$.

Reconfigurable and modular solutions for final assembly systems need equally modular design tools. Each modular building block of the real system needs to have a digital image to be used in simulation model building, reconfiguration and analysis. Component-based simulation software with 3D capabilities is ideal for the design and configuration of modular reconfigurable systems. 


\subsection{Life-cycle consideration}

As mentioned earlier, we need to calculate all the costs arising during the lifetime of the equipment. Some ideas for figuring out the frequency of change of assembly systems are given in Table 1. Typically the fastest changes occur in computer manufacturing and consumer goods. A change could occur at 6-month intervals. The life cycle is longer in the automobile industry, and especially in military or medical applications.

To be cost efficient the assembly system needs to outlive the product it was originally designed for, and here there is a need to analyze the life cycle of the planned system. The life cycle estimations of the system in the design phase are based on scenarios created by the end-user. Usually end-users have product roadmaps and estimations for new variant or product family introduction. Thus engineers can estimate the different products and variant life in production and also estimate the changes needed for the assembly system. If the basic assembly process is the same, only the product-specific system parts need to be changed, such as gripper fingers, part feeding, etc.

The scenarios can be modeled with a simulation tool that supports modularity. Each planned change of the system is modeled, and by comparing models it is possible to estimate the needed equipment changes to the system. This approach is useful in the new product introduction phase, when engineers are adapting the new product to the existing assembly line.

Currently there are requirements for common processes worldwide, and engineers need to analyze different country locations and assembly concepts. The cost of labor is but one parameter; there are others affecting unit costs in different locations. The number of good products produced depends on the efficiency and quality performance of the planned assembly system.

\subsection{E-Race analysis toolkit theory, COO and OEE}

The basics of COO are simple - it is all of the costs during the system life-cycle divided by the number of good-quality units produced ${ }^{1,7,8,9}$. Thus $\mathrm{COO}$ depends on the production throughput rate, equipment acquisition cost, equipment reliability, maintenance, equipment utilization, throughput, yield, rework and scrap cost and useful life-time of the system. The basic COO is given by the following equation:

$\mathrm{COO}$ per unit $=$ total cost $/$ number of good-quality products .

$$
\mathrm{COO}=(\mathrm{FC}+\mathrm{VC}+\mathrm{YC}) /(\mathrm{L} \times \mathrm{THP} \times \mathrm{Y} \times \mathrm{U})
$$

Where:

$\mathrm{FC}=$ Fixed costs (amortized for the period under consideration) 


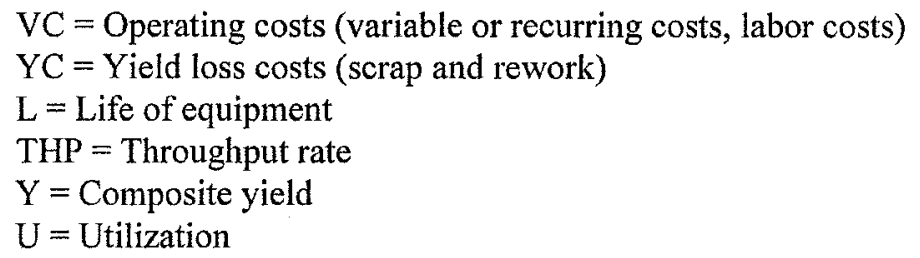

The basic equation for calculating the $\mathrm{COO}$ was originally developed for wafer fabrication tools and has become a common reference between equipment suppliers and equipment users in the semiconductor industry. In the arena of electromechanical assembly, it is virtually unknown even though similar calculations are used. Use of the $\mathrm{COO}$ is an implementation of Activity-Based Costing ( $\mathrm{ABC}$ ) that helps in understanding all costs associated with a decision. It improves decisions by relating costs to the products, processes, and services that drive cost. Without such a linkage, it is difficult for organizations to understand the full impact of their decisions on their operating cost structure. With this linkage, $\mathrm{COO}$ provides a consistent data-driven method for arriving at important strategic and operational decisions. The difficulty is how to evaluate system flexibility, product mix, modularity and the re-use value of the system.

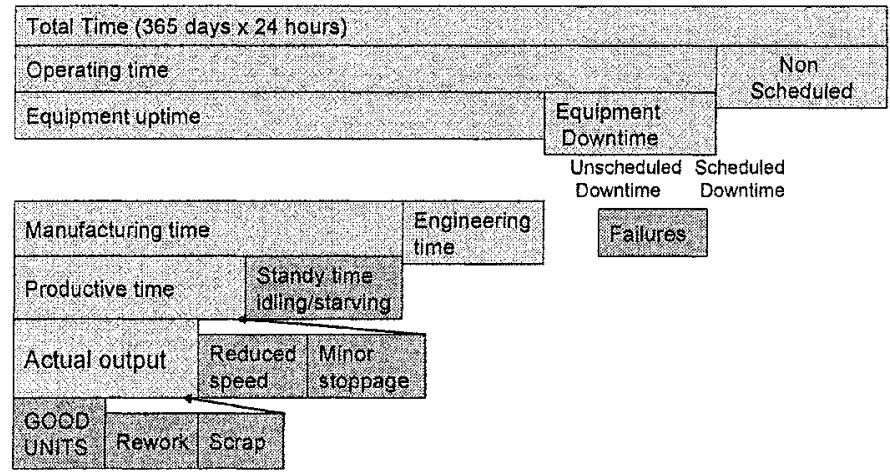

Figure 2. OEE helps to calculate the number of good units produced.

Authors are using OEE analysis to calculate numbers of good-quality products (Figure 2). The OEE (Overall Equipment Efficiency) is commonly used for monitoring the running performance of shop floor equipment. It was developed as an equipment effectiveness metric in Japan to measure the effectiveness of a manufacturing technique called Total Productive Maintenance (TPM). Originally, it was called Overall Equipment Effectiveness. The Semiconductor Equipment and Materials International (SEMI) Metrics Committee changed it to Overall Equipment Efficiency. 
OEE is a key performance indicator of how machines, production lines or processes are performing in terms of equipment availability: reliability (MTBF), maintainability (MTTR), utilization, throughput performance or speed and quality produced. It identifies losses due to equipment failure, setups and adjustments, idling and minor stops, reduced speed, process defects and start up. All the above factors are grouped under the following three submetrics of equipment efficiency:

1. Availability

2. Performance efficiency

3. Rate of quality

The three sub-metrics and OEE are mathematically related as follows:

$\mathrm{OEE}, \%=$ availability $\mathrm{x}$ performance efficiency $\mathrm{x}$ rate of quality $\mathrm{x} 100$

General information about OEE can also be obtained from www.oee.com ${ }^{10}$. There are different opinions on how to calculate OEE. The developed Overall Equipment Efficiency analysis method used by the authors is based on a standard ${ }^{2,3}$. There is a systematic way to classify and study equipment efficiency and time losses.

\section{$2.4 \quad$ E-Race VTT analysis toolkit prototype}

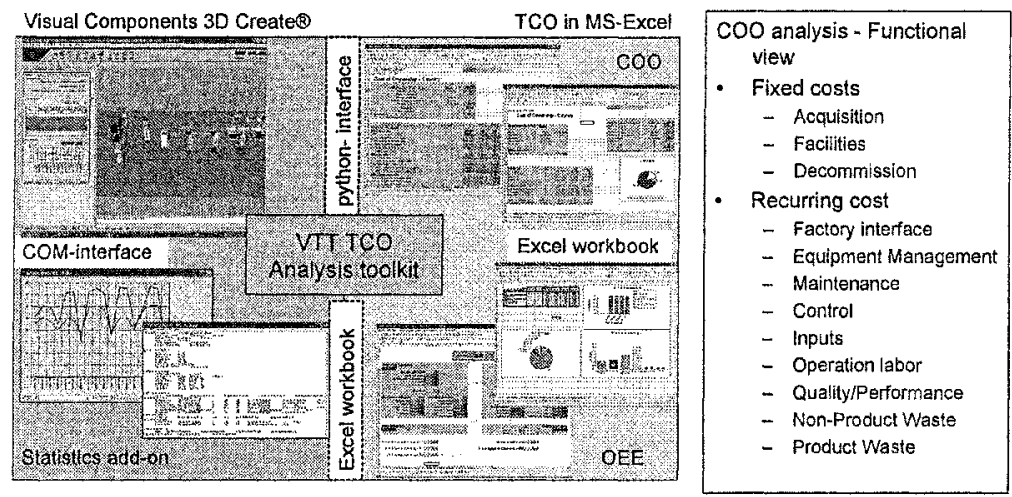

Figure 3. TCO VTT Analysis toolkit integrated into component-based simulation

Based on the standardized methodology presented here, the authors have developed a TCO, Total Cost of Ownership analysis Excel workbook ${ }^{8}$. Only suitable calculation formulas and definitions from selected standards ${ }^{1,2,3}$ are used and the method is adapted for electromechanical final assembly system design evaluation. The users can input the parameters to the Excel sheets and analyze TCO, COO and OEE values. 
In the second prototype tool', the authors have also integrated commercial component-based simulation (www.visualcomponents.com ${ }^{11}$ ) into TCO Excel analysis workbooks. An overview of the integration is shown in Figure 3. Each time an engineer selects a component from eCatalogue and places it on a simulation model layout, the cost functions start adding equipment cost, and adding an operator to the model adds to the labor cost function. The current version uses a COM interface, Python scripts, and Excel-internal links. Integration of Total Cost of Ownership (TCO) analysis into the simulation provides an effective method for evaluating system alternatives from a cost standpoint. This is clearly a tool for the system sales engineer. Adding easy-to-use cost analysis features to the simulation improves the quality of decisions during a sales meeting.

\section{A CASE STUDY}

The scenario presented here is based on discussions with industrial partners. The initial data is briefly the following: study of the final assembly line, making Product B (Basic) and later on Product A (Advanced). In all scenarios the production country is Finland, the worker cost of a year is 49 $504 €$, the cost of floor space is $200 € / \mathrm{m} 2$ /year, and the needed floor space is $200 \mathrm{~m} 2$. The cost of rework is estimated to be $20 €$. Cycle time of the bottleneck machine is in all cases $7 \mathrm{~s}$. The calculated volume of good-quality units with one shift, 5 working days per week, is 7286765 units/year. The OEE factors are: Availability Efficiency $21.19 \%$, Performance Efficiency $77.73 \%$, and Quality Efficiency $98.45 \%$.

The first scenario is to calculate what happens if two separate dedicated assembly lines are built. Figure 4 shows layouts and Tables 2 and 3 list some input data and major results.
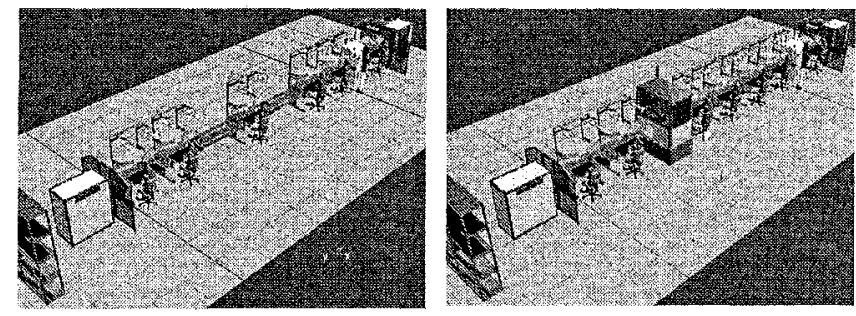

Layout 1, Product B, Basic Layout 2, Product A, Advanced

Figure 4. Layouts to be analyzed were modeled with a simulation tool. 
Table 2. Comparison Product B (Basic) and Product A (Advanced), 5 years production

\begin{tabular}{lrr}
\hline & Product B (Basic) & Product A (Advanced) \\
\hline Number of workstations & 7 & 9 \\
Number of workers & 6 & 7 \\
Number of support workers & 1 & 1 \\
System price & $156000 €$ & $222000 €$ \\
Cost of product components & $10.00 €$ & $12.50 €$ \\
Fixed Costs (all costs) & $515424 €$ & $581424 €$ \\
Recurring Cost (components, labor, etc.) & $41216928 €$ & $50572898 €$ \\
Yield loss cost (scrap, rework) & $821313 €$ & $898651 €$ \\
Total costs & $42553665 €$ & $52052973 €$ \\
COO & $11.68 € /$ unit & $14.29 € /$ unit \\
\hline
\end{tabular}

Table 3. Life-cycle cost for Product B (Basic) for 5 years

\begin{tabular}{lrrrrr}
\hline & Year 1 & Year 2 & Year 3 & Year 4 & Year 5 \\
\hline Fixed & 267808 & 59904 & 59904 & 59904 & 67904 \\
Recurring & 9312672 & 7976064 & 7976064 & 7976064 & 7976064 \\
Yield loss & 164263 & 164263 & 164263 & 164263 & 164263 \\
Total costs & 9744743 & 8200231 & 8200231 & 8200231 & 8208231 \\
Cumulative COO & 13.37 & 12.31 & 11.96 & 11.78 & 11.68 \\
\hline
\end{tabular}

Table 4. Work time (availability), volume effect on cumulative COO

\begin{tabular}{lrrrrr}
\hline Yearly volume & Year 1 & Year 2 & Year 3 & Year 4 & Year 5 \\
\hline 5 shifts/728 676 unit & 11.37 & 12.31 & 11.96 & 11.78 & 11.68 \\
10 shifts/1 550 952 unit & 11.92 & 11.42 & 11.25 & 11.17 & 11.12 \\
15 shifts/2 393 040 unit & 11.46 & 11.13 & 11.03 & 10.97 & 10.94 \\
21 shifts/3 364 712 unit & 11.30 & 11.07 & 10.99 & 10.96 & 10.93 \\
\hline
\end{tabular}

Different work time arrangements show the capacity flexibility of the system and the effect on the cumulative COO (Table 4). The effects of maintenance costs were not evaluated in detail. Value-added cost can be calculated by subtracting component costs from the $\mathrm{COO}$ value. Similar results can be calculated for each layout and selected product and working time scenario. There are many variable parameters available in the TCO analysis workbook.

To continue the scenario, the next step would be to analyze a flexible assembly line capable of assembling two products. This is one way to justify flexibility or automation or at least find acceptable investment threshold values.

\section{CONCLUSION}

This article presents a case study in the design of a modular reconfigurable final assembly system using simulation, system life cycle and cost analysis methodology. The theory behind the analysis is also briefly 
explained. The developed TCO prototype tools are currently proof of the concept. There is a similar commercial tool available, dedicated for the semiconductor industry, at www.wwk.com ${ }^{12}$.

Cost of Ownership (COO) provides an objective analysis method for evaluating decisions. COO provides an estimate of the life-cycle costs. The analysis highlights details that might be overlooked, thus reducing decision risk. $\mathrm{COO}$ can also be used for evaluation of processing and design decisions. Finally, $\mathrm{COO}$ allows communication between suppliers and users. They are able to speak the same language, comparing similar data and costs using the same analysis methods. Both suppliers and manufacturers can work from verifiable data to support a purchase or implementation plan.

The lifetime cost of ownership per manufactured unit is generally sensitive to production throughput rates, overall reliability, and yield. In many cases, it is relatively insensitive to initial purchase price, as shown by the example. With correct parameters an engineer can justify investments to flexibility and automated equipment or at least determine threshold values.

Overall Equipment Efficiency is usually a measurement of singlemachine performance. In the example presented, the calculations are used for a bottleneck machine, and in practice the Overall Throughput Efficiency of the assembly line is calculated. With a serial line and single product, this can be quite simple. The analysis is more complex with mixed production and layout with parallel operations. Simulation studies can pinpoint bottleneck equipment. One of the limitations using OEE analysis is that analysis is process or equipment centric and the material flow or work in process (WIP) is not analyzed, another reason to use factory simulation.

For future development, real case studies with industrial partners are in progress in a new research project. The aims are to improve integration of the analysis into the component-based simulation software, to obtain analysis data from simulation input data files, and from the results of simulation runs with minimum effort from the users.

Users should remember that, as with all simulation analysis, this kind of simulation is sensitive to input data, and that input of false information does not produce the right results. The challenge is getting correct data. Knowing this, the authors are not aiming at absolute results in the design phase but, rather, at obtaining data for comparison of design alternatives. Later on, real factory data and accounting data can be used to verify the models and thus improve the results in the next evaluation round and new system designs.

The authors believe that $\mathrm{COO}$ and $\mathrm{OEE}$ are becoming increasingly important in high-tech decision-making processes. The challenge is to bring system reconfiguration to the analysis automatically; the idea exists at the 
conceptual level. Now, reconfiguration and system modularity cost efficiency analysis requires a lot of manual work.

\section{ACKNOWLEDGEMENTS}

The development presented here is part of the Eureka Factory E!-2851 ERace project ${ }^{13,14}$. The authors wish to acknowledge the financial support received from the National Technology Agency of Finland (Tekes), VTT, and Finnish industry. The national project consortium in Finland, research institutes, technology providers, and end-users are working together to enhance assembly systems design methodology and to create nextgeneration assembly systems.

\section{REFERENCES}

1. SEMI E35-0701, Cost of Ownership for Semiconductor Manufacturing Equipment Metrics, SEMI International Standard, http://www.semi.org

2. SEMI E10-0304, Specification for Definition and Measurement of Equipment Reliability, Availability, and Maintainability (RAM), SEMI International Standard, http://www.semi.org.

3. SEMI E79-0304, Specification for Definition and Measurement of Equipment Productivity, SEMI International Standard, http://www.semi.org.

4. Assembly Survey 2004. Assembly Magazine, December 2004, p36 or (www.assemblymag.com).

5. Chow (1990): We-Min Chow. Assembly Line Design, Methodology and Applications. Marcel Dekker, Inc., New York and Basel, 1990.

6. iNEMI Technology Roadmaps 2004 Edition. Final Assembly. International Electronics Manufacturing Initiative. December 2004.

7. Ragona, Sid (2002). Cost of Ownership (COO) for Optoelectronic Manufacturing Equipment. 2002 Microsystems Conference. Rochester, New York, p. 200.

8. J. Heilala, K. Helin, J, Montonen. Total Cost Of Ownership Analysis For Modular Final Assembly Systems. 18th International Conference on Production Research. 30.7.4.8.2005, Italy, Salerno.

9. J. Heilala, K. Helin, J. Montonen, P. Voho, M. Anttila. Integrating Cost of Ownership Analysis into Component-Based Simulation. 1st International Conference on Changeable, Agile, Reconfigurable and Virtual Production 22-23.9.2005. Munich, Germany

10. www.oee.com

11. www.visualcomponents.com.

12. www.wwk.com

13. E-Race Finland 2002-2006, project brochure.

14. www.e-race.info, international project Web site. 